\title{
Publishing, publications and African psychiatry
}

Africa is a diverse continent, incorporating many races, cultures and religions. In addition, levels of development and infrastructure vary from country to country as well as between regions within countries. In this sense, African psychiatry cannot readily be thought of in a uniform way. However, common to all countries on the continent are issues of resources and capacity. This applies both to what the continent has as well as what it does or doesn't have access to. Against this background the issue of publishing and publications with regard to African psychiatry will be reviewed, specifically in terms of the status quo, current shortfalls and future directions.

It is well to embark on this review with some facts and figures, given that putting Africa in context is critical to the understanding of the challenges that lie ahead. All of the information in this regard is derived from a publication of the Economist (2007). ${ }^{1}$ Spending on health, as a proportion of Gross Domestic Product (GDP) is a useful departure point. GDP is the monetary value related to production of goods and services, in a given country, used both as an indicator of economic activity as well as the extent of development, purely in terms of economic welfare, of that country. Using the United States of America (USA) as a "gold standard" in terms of the developed world (which it might not necessarily be), only South Africa and The Gambia, on the African continent, come close in terms of percentage of GDP spent on health with $8.1 \%$ for each country compared to $15.2 \%$ for the USA. This against a background of more general spending on health in the region of 2-3.7 \% for Congo-Kinshasha and Mauritius respectively, with Madagascar and Angola slightly more than Mauritius and Sierre Leone and Cote d'Ivoire just less than Mauritius. When comparing the population per doctor, Cuba and Estonia with 170 and 212 people per doctor in each country respectively appear somewhat over serviced when compared to African countries where for example CongoKinshasha has 71958 population per doctor, Mozambique 37 354, Sierra Leone 30952 and Lesotho 20 225. Reviewing health indicators, comparing developed countries (in this instance the USA and Germany), as well as selected African Countries (Egypt, Kenya, Nigeria, South Africa and Algeria) a picture emerges that reveals variation between developed countries as well as between developed and developing countries and between developing countries. The measures used were those of: health spending as a percentage of GDP, the number of doctors and the number of hospital beds per 1000 population. For each country, the figures for each aforementioned dimension were as follows - USA: 15.2, 2.5, 3.3; Germany: 1 1.1 , 3.4, 8.9; Egypt: 5.8, 0.5, 2.2; Kenya: 4.3, 0.1, unknown; Nigeria: 5, 0.3, unknown; South Africa: 8.4, 0.8, unknown; Algeria: 4.1, 1.1, 2.1. Within the African context, South Africa spent the most on health care as a percentage of GDP and had the most number of doctors per 1000 population. Amidst all the data, the Human Development Index, which emerged in 1990 from the United Nations Development Programme, was an attempt to move beyond purely economic measures to determine development and incorporated not only GDP but also levels of adult literacy and life expectancy. Any country scoring above 80 had a high level of human development, those scoring 79-50 a medium and any country below 50 a low level. In terms of this measure Norway scored the highest at 96.3, with Brazil scoring 79.2. Amongst a range of African countries, none scored above 50 with scores of 44.5 for Angola, 42 for Cote d'Ivoire, 37.9 for Mozambique and 28.1 for Niger. Finally, measuring "quality of life" which is an index based on 39 factors ranging from recreation to political stability, not one African city was amongst the 40 highest cities whereas 23 of the lowest 40 cities were African. Overall, the indicators tell us that Africa has quite some catching up to do, in general, in terms of both the health sector and quality of life relative to the so called developed world. Further, that within Africa there are various levels of spending and development, providing a perspective on the earlier noted diversity.

It is not difficult on the basis of the aforementioned data to jump to conclusions regarding the welfare of Africa. In some respects, making it justified to stereotype Africa as a continent grappling with challenges that appear insoluble. What of African psychiatry? There are both myths and ultimately realities. A recent editorial, by Gureje, highlighted aspects of both most eloquently, specifically that rates of psychiatric disorders which were thought to be less in African populations than elsewhere are indeed no different; that somatization, thought to be more prominent in African populations than others, is no different; that stigma, thought not to be a phenomenon in African communities, is present as in other societies; and that outcomes in Schizophrenia, thought to be better amongst African populations, remains contentious although yet to be refuted. And yet, there are some documented differences. Specifically in relation to Alzheimer's disease which appears to be less prevalent amongst the Yoruba people of Nigeria compared to the rest of the world, specifically compared to African Americans who share genetic material. This finding highlights potential environmental or cultural factors that may influence the occurrence of this disease. ${ }^{2}$ Behind each of the aforementioned findings is science. African science, albeit collaborative. Speaking of science raises the issue of academia. It seems that there are global concerns in this regard. Within the South African context it has been suggested, in relation to psychiatry, that if there is no academic psychiatry there will be no psychiatry. ${ }^{3}$ The context of that opinion had been a critical analysis of the implications for staff who are jointly appointed, in terms of clinical (state) and academic functions (university) but caught between 
service demands from either domain whilst directly paid by the health authority for whom clinical service is rendered. The concern was that on the basis of such a funding situation, without clear policy regarding defined academic time, academia would lose. Yet concerns of this nature have been voiced in both the USA and Europe, where in the USA the death of the US academic medical centre has been feared on the basis of hundreds of millions of dollars in budget being cut due to such research being viewed as an expensive luxury. ${ }^{4}$ The European view, as espoused by the International Campaign to Revitalize Academic Medicine (ICRAM), is that academic medicine has lost it's way. This on the basis of no retention or recruitment of the best personnel; having no vision for the future; a debasement of values where medicine is a business; a disconnection from the stakeholders, both the public as well as health care practitioners and a lack of global outlook with no meaningful attempt to close the gap between rich and poor. ${ }^{5}$ Given such developed world concerns, it is interesting to note that a debate related to excellence in Africa exists. A series of articles carried by the Science and Development Network website in December 2006 related to African centres of excellence. These are the planned "Nelson Mandela Institutes" which are to comprise a number of centres also to be known as the African Institute for Science and Technology, the first of which is due to open in Abuja, Nigeria in 2007 with others to follow in both Burkino Faso and Tanzania. Opinion is divided, ranging from concerns that these institutes will concentrate development in just a few countries and the rest will stagnate ${ }^{6}$, to support for the concept with the understanding that countries would need to invest at least 1-4\% of Gross National Product (GDP plus income derived from abroad) in science and technology. ${ }^{\text {? }}$ Others have felt that rather than investing in and creating new institutions, money would be better spent on strengthening existing ones. ${ }^{8}$

Against this background, we move to the subject of publishing in Africa, specifically focusing on psychiatry as a medical discipline and encompassing both journals and textbooks. Regarding the latter, two recent publications come to mind i.e. "Essentials of Clinical Psychiatry for sub-Saharan Africa" published in 2006 and the more recent "The African Textbook of Clinical Psychiatry and Mental Health" published in 2007. The former under the auspices of the World Psychiatric Association (WPA) and the African Association of Psychiatrists and Allied Professionals (AAPAP) and the latter published by the African Medical Research Foundation (AMREF). Both textbooks have succeeded in bringing together a diverse range of authors from within the African continent with either book aiming to create content written by Africans, for Africans. In terms of journals, as of 2005, a study identified 158 medical journals active in 33 countries in Africa. ${ }^{9}$ Four countries accounted for over half of the publications i.e. 88 of the 158, and these were Nigeria (33), South Africa (26), Egypt (18) and Kenya (11). Of the publications identified, 4 related to mental health and whilst not specified it is possible that all were South African publications in the form of South African Psychiatry Review, the South African Journal of Psychiatry, the South African Journal of Psychology and the Journal of Child and Adolescent Mental Health. Of the identified publications, 59 were surveyed. Of these 51 were in English, 7 in French and 1 in Portuguese, with the majority (41/59) having circulations of fewer than 1000 and frequency of publication being 4 or fewer editions per year (52/59). Only a minority were indexed in either medline (18/59) or Embase (10/59). Based on the research a couple of salient issues emerged i.e. that database representation is poor and visibility is low. A number of reasons were cited that related to: quality of research (poor), regularity of publication (infrequent) and accessibility (limited). The latter two factors spoke of the lack of infrastructure whereas quality of research was seen to be a function of lack of expertise. Beyond these constraints, a number of other potential threats to publishing exist. Specifically the emergence of online international medical journals, which might undermine indigenous publishing and publications, and government interference or indifference. In terms of the latter, and within the South African context, the Academy of Science of South Africa (a governmental organization) recently published a report that focused on a strategic approach to publishing in South Africa. ${ }^{10}$ Distilling the content, which was based on a survey of existing publications (both medical and non-medical), the critical point that emerged related to there needing to be a focus on excellence with a potential reduction in the number of Department of Education (DoE) accredited journals. Certainly this would cut costs in terms of subsidies paid out by the DoE for material published in accredited journals, but would it benefit the scientific community in terms of promoting scientific endeavour ? A developmental approach with clearly articulated goals for raising the standard of all existing publications might have been more reassuring. With regard to medical publications, the authors of the report noted that less than $20 \%$ of the content of the South African Medical Journal was in fact peer reviewed material. The open access era is upon us and this has certainly created opportunity whilst at the same time posing a threat. As much as the existence of online versions of international journals may sound appealing, you need to be a subscriber i.e. there remains a cost, certainly for current material. Yet there is significant opportunity in the area of open access, specifically in relation to the international versus local content debate. It has been argued that we need to recognize local journals as a resource for health, insofar as publishing in well established journals from developed countries renders such material inaccessible to developing countries. ${ }^{11}$ Further, that locally relevant research is required in order to provide context for evidence that guides practice. ${ }^{11}$ Local journals are thus relevant, providing a local focus and evidence that can be vewed within the context it is derived from. Moreover it needs to be recognized that so-called "international" journals are seldom truly international in their editorial boards, readership or content. ${ }^{11}$ There is a tendency to overestimate just how international they really are, with many such journals being quite parochial and speaking to their own interests unless there is political capital to be gained from speaking to other interests (it seems). With this in mind, there needs to be an investment that contributes towards sustainability of local publications and in this regard, open access may be particularly advantageous in terms of some of the limitations noted earlier ${ }^{9}$ and should be promoted. ${ }^{11}$ Within the discipline of psychiatry, one international publication stands out in this regard i.e. World Psychiatry, which is the official publication of 
the WPA and is available as an open access publication without a subscriber fee. It has been noted that medical journals in lower and middle income (LAMI) countries publish a significantly smaller proportion of articles related to psychopathology than their counterparts in high income countries, although there does appear to be an increase which probably reflects local governmental priorities in relation to mental health. ${ }^{12}$ Accordingly the authors of this study felt that LAMI countries should be encouraged to increase such research i.e. on psychiatric disorders, a noble sentiment. Further, that such findings should be published in both regional and international medical journals.

In support of African science and publishing a number of initiatives exist, all of them internationally driven it seems. Those that are most prominent include: The Forum for African Medical Editors (FAME), a World Health Organization (WHO) initiative which has a focus on scientific writing; The African Index Medicus (AIM), another WHO initiative, which aims to create a data base akin to medline, for African publications; African Journals Online (AJOL) which is supported by the United Nations (UNESCO) and provides a database of African publications (both medical and non-medical) with access to both journal profiles and abstracts. Through AJOL one has been able to establish interest in the two South African journals related to psychiatry in terms of the number of "hits" over a specified period. For the period 2004-2005, South African Psychiatry Review had 19311 and the South African Journal of Psychiatry had 2057. Beyond Africa, as a specific focus, but within the context of developing nations other initiatives include: The International Network for the Availability of Scientific Publications (INASP) which is another UNESCO supported organization promoting open access; The Health InterNetwork Access to Research Initiative (HINARI), which was launched by the WHO in 2002 and currently involves some 70 publishers to provide free, or very low cost, online access to the major journals to local, not-for-profit institutions in developing/low income countries. South Africa is excluded from free access as it does not meet the definition of low income i.e. GNP per capita below $\$ 1000$. Finally, there is the Science and Development Network (SciDevNet), supported by both "Nature" and "Science" as well as various international organizations from the UK, Sweden and Canada. This organization publishes a weekly electronic update of scientific developments in Africa as well as other developing countries. It should be noted that in 2006, 3 additional African titles were added to medline i.e. Mali Medical, SAHARA Journal and the Tanzanian Health Research Bulletin (Pippa Smart, Personal communication, 16 February 2007), all of which were well established journals of interest in terms of data related to number of "hits" for the period 2004-2005 from AJOL.

Development requires, amongst others, two components. These are the building of a scientific knowledge base, which is crucial, and access to scientific information, a key element. A major problem is cost of access. ${ }^{13}$ Beyond the aforementioned components for development, mental health is a very specific requirement insofar as it "...is linked to the development of key sectors, such as education..". ${ }^{14}$ This quote is taken from an editorial which appeared in the Lancet, authored by one of Africa's most prominent academic psychiatrists, Oye Gureje. The question is whether it will reach the audience it should. The authors were looking at the role of mental health in development, beyond the components of the Human Development Index (HDI) mentioned earlier. In relation to education they were referring to the formal sector of which academic publishing is surely a part. Further, if human development requires mental health and mental health is linked to education, surely by inference the role of publishing and publications cannot be ignored.

Open access, as promoted by INASP and others, has really been about "us" (developing) accessing "them" (developed) although more recently with the advent of organizations such as Bioline International the emphasis has been on creating windows of exposure for "us" to whoever. The idea is that true open access entails unrestricted access to scientific information; that through such access and given the contributions that can be made from both the developed and the developing world, equity is promoted i.e. developing countries do not simply gain. There are unquestionably advantages associated with open access with more frequent citations as well as ultimately greater impact. ${ }^{15}$ But who will fund it? Whilst organizations such as Bioline International exist, they are non governmentally, university funded and thus limited in their capacity to host publications. Surely institutions, or alternatively governments, should create such opportunities for their scientific communities? A recent study into access to electronic sources of health information amongst african postgraduate doctors and research scientists, revealed that most reported textbooks as their main source of information. ${ }^{16}$

It is well to reflect on the following statement:

"...the lack of an indigenous base of science and technology will hamper Africa's development as surely as any stupid ideology or greedy dictator.'.'17

Resource allocation in terms of publications is critical to the promotion, and communication of, an indigenous knowledge base. The responsibility lies with Africans. It is imperative that there is appropriate recognition of the need, and accordingly the priority, with a commitment in terms of not only policy but also funding. Some Africans have argued that the continent has been crippled by what Steve Biko called the "colonization of the mind", but countries that prosper tend to do so as a consequence of their own efforts. ${ }^{18}$ With this in mind, one does not need to look too far for clear guidance, in fact no further than Thabo Mbeki, the South African president who in predicting the African Renaissance said that such a renaissance would only succeed "..if its aims and objectives are defined by the Africans themselves, if its programmes are designed by ourselves and we take responsibility for the success or failure of our policies..". 18

On such a note, and bearing in mind the sentiments expressed by the writer Zakes Mda that "The African identity is a novel phenomenon. It is an identity in the making'19 and all that has been said, it is fitting to welcome you to the first edition of the African Journal of Psychiatry, an official publication of the African Association of Psychiatrists and Allied Professionals (AAPAP). An African voice, for African Psychiatry.

Christopher P. Szabo Editor-in-Chief African Journal of Psychiatry 


\section{References}

1. The Economist. Pocket World in Figures, 2007 edition. London: Profile Books Ltd, 2007.

2. Gureje, O. Psychiatry in Africa: the myths, the exotic, and the realities. South African Psychiatry Review 2007; 10: 11-14.

3. Szabo CP. Psychiatry in South Africa: some reflections. South African Psychiatry Review 2006: 9: 121-125.

4. The Lancet. The death of the US academic medical centre? The Lancet 2007; 369: 532.

5. Ioannidis JPA, Ahmed T, Awathi S, Clarfield AM, Clark J, Dandona L, et al. Open letter to the leader of academic medicine. British Medical Journal 2007; 334: 191-193.

6. Lewanika MM. Centres of excellence: not ideal for African science. SciDev.Net, 13 December 2006.

7. Soboyejo W. A network of excellence for African development. SciDev.Net, 13 December 2006.

8. Matos N. African science: in with the old, out with the new. SciDev.Net, 13 December 2006.

9. Siegfried N, Busgeeth K, Certain E. Scope and geographical distribution of African medical journals active in 2005. South African Medical Journal 2006: 96: 533-538.

10. Academy of Science of South Africa. A Strategic Approach to Research Publishing in South Africa. 2006. wWw.assaf.org.za
11. Ofori-Adjei D, Antes G, Tharyan P, Slade E, Tamber PS. Have online international medical journals made local journals obsolete? PloS Medicine 2006; 3(8): e359. DOI: 10.1371/journal.pmed.0030359

12. Ipser JC, Stein DJ. Little mental disorder research in general medical journals in low- and middle- income countries. South African Medical Journal 2007; 97: 110-111.

13. Agosti D. 'Free' access to research should not be limited. SciDev.Net, 28 December 2006.

14. Gureje O, Jenkins R. Mental health in development: re-emphasising the link. The Lancet 2007; 369: 447-448.

15. Eysenbach G. Citation advantage of open access articles. PLoS Biol 2006; 4(5): e157. DOI: 10.1371/journal.pbio.0040157

16. Smith H, Bukirwa H, Mukasa O, Snell P, Adeh-Nsoh S, Mbuyita M, et al. Access to electronic health knowledge in five countries in Africa: a descriptive study. BMC Health Services Research 2007; 7(72): doi:10.1186/1472-6963-7-72

17. The Economist. Amaizing grace. The Economist February 3rd 2007, 13.

18. Guest R. Introduction: Why is Africa so poor? In: The Shackled Continent, Africa's Past, Present and Future. London, Macmillan, 2004, 10-11

19. Mda Z. Creating a continental identity. In: Weekend Review, The Weekender, May 26-27 2007, 8-9.

\title{
SANOFI AVENTIS GRANT
}

It is with great pleasure that we announce the award of the Sanofi Aventis educational grant, valued at R50 000, for the period: May 2006-May 2007.

After consideration of the eligible articles for the period of review,

by the board members of South African Psychiatry Review,

it was decided that the grant will be awarded to:

"Cannabis and other variables affecting age at onset in a schizophrenia founder population."

Authors: Roos, J.L.; Pretorius, H.W.; Karayiorgou, M.; Boraine, H.; Published: 2006

From: South African Psychiatry Review, Vol 9, Issue 2, May, Pages: p.99-103

Our heartfelt congratulations to the authors!

\author{
Christopher P. Szabo \\ Editor-in-Chief \\ $\&$ \\ Leverne Jonas \\ sanofi aventis
}

